\title{
What Do We Know about the Use of EEG Monitoring during Equine Anesthesia: A Review
}

\author{
Olga Drewnowska ${ }^{1, *}$, Barbara Lisowska $^{2}\left(\mathbb{D}\right.$ and Bernard Turek ${ }^{1}(\mathbb{C}$ \\ 1 Department of Large Animals Diseases with Clinic, Faculty of Veterinary Medicine, Warsaw University of \\ Life Sciences, Nowoursynowska 100, 02-797 Warsaw, Poland \\ 2 National Geriatrics, Rheumatology and Rehabilitation Institute, Spartańska 1, 02-637 Warszawa, Poland \\ * Correspondence: vet.olgadrewnowska@gmail.com; Tel.: +48-608-709-346
}

Received: 8 August 2019; Accepted: 28 August 2019; Published: 5 September 2019

Featured Application: The potential use of a real-time EEG measurement during equine anesthesia monitoring as a complimentary method to current approaches (including hemodynamic and respiratory parameters).

\begin{abstract}
Electroencephalography is a noninvasive method used for the measurement of central nervous system bioelectrical activity. Besides its use for neurological disorders diagnostics in humans and animals, it was found to be useful as a part of the anesthetic monitoring. Introducing the electroencephalography (EEG) measurement intraoperatively in humans and in animals, due to its high specificity and sensitivity (limited number of wave patterns and high number of variabilities influencing them), with comparison to cardiovascular parameters might significantly increase the quality of anesthesia. The use of EEG during equine anesthesia may help to maintain a proper depth of anesthesia in this species. Due to the fact that EEG analyzers were designed for humans, there are still limitations of their use in horses, and different methods of analysis are studied. The paper introduces the physiology of EEG, its use in animals during anesthesia, and specification for horses.
\end{abstract}

Keywords: EEG; equine anesthesia; anesthesia monitoring

\section{Introduction}

Electroencephalography (EEG) is a relatively simple and noninvasive method used for measuring the bioelectric activity of the central nervous system (CNS). Its discovery became a breakthrough in many aspects of medicine, as it allowed one to determine the place of the primary nervous stimulus formation in the cerebral cortex [1]. Currently, EEG is widely used in diagnostics of neurological disorders, but it has been also introduced into other branches of medicine, including anesthesiology [2]. Even though it has been used to assess depth of anesthesia in many animal species, the validity of its usage is still not clear. EEG measurement as a part of anesthetic monitoring, which till now included only recording of physiological parameters, can significantly change the management of general anesthesia and the possibility of assessment of its depth [3,4].

The EEG study was first described by the German neuropsychiatrist Hans Berger in 1929. His research included detecting neurological disorders in people like epilepsy [5,6]. However, as early as in 1960, the first attempts to carry out this type of research in animals were made, also focusing on the detection of neurological disorders [7-10]. Within decades, new techniques of diagnostics of nervous system were introduced such as magnetic resonance imaging (MRI) and computed tomography (CT), which gained more attention due to their accuracy. However, the use of EEG is still popular with clinicians because its use is simple, it indexes the temporal dynamics of the brain with millisecond precision and allows to assess physiological changes while MRI and CT show imaging changes and 
need time to process the findings. In addition, in contrast to the EEG, both imaging methods are not applicable during routine surgery.

\section{Physiology of Brain Activity-Why Is the EEG so Important in the Management of Anesthesia?}

The nervous system can be divided into so-called levels, described by MacLean as the triune model of the brain. The lowest level of response to stimuli consists of the spinal cord centers, which control reflexes (also muscle tone, reflex reactions of blood vessels). The next one is the lower brain level (subcortical) with reticular formation of the medulla oblongata, midbrain vestibular nucleus, hypothalamus, and limbic system. They are responsible for maintaining blood pressure, breathing pattern, and the position of the eye. The highest in the hierarchy is the higher (cortex) level with the cerebral cortex, coordinating all brain functions including the sight, hearing, and other complex activities, apart from reflex reactions controlled by lower centers [11,12]. The sympathetic and parasympathetic systems are associated with all brain levels through afferent and efferent pathways in all organs, with a different predominance. They control organs by reflexes and through cortical and other central control centers-some of the functions controlled are heart rate, arterial diameter, regulation of the urinary bladder, and tracheal diameter, which are measured as vital signs during anesthesia [13].

Electroencephalography signal is generated by rhythmic neural sources that are spontaneous per se but also act as regular oscillators. Their source is in the cerebral cortex, exactly in its layer of pyramid cells [1] partially modulated by glial cells [12]. The cerebral cortex is responsible for many key functions such as learning and cognitive processes [14]. In addition, it has been shown that the cortex is stimulated during the action of nociceptive stimuli [15], which is important in anesthetic monitoring. The impulses recorded during the EEG measurement are the sum of electrical signals originating from neurons within the cerebral cortex and as a result of postsynaptic potentials in the neurons located in the lower layers of the cortex [2]. The excitation and inhibitory potentials are distinguished, according to the effect of the type of neuroreceptor, that is stimulated [16].

The frequency and amplitude of the EEG is modulated by the nuclei of the thalamus, which transduces peripherally received signals to the cortex and between its parts. It is generally assumed that the signals measured by the EEG are proportional to the level of consciousness and their frequency decreases with the deepening of the level of anesthesia [16]. The EEG frequency ranges that can be used to determine the level of general anesthesia are:

- $\delta(0-4 \mathrm{~Hz})$ - with a large amplitude, characteristic for deep sleep or anesthesia

- $\theta(4-8 \mathrm{~Hz})$-observed in light sleep or anesthesia

- $\quad \alpha(8-13 \mathrm{~Hz})$-in awake but relaxed state

- $\quad \beta(13-30 \mathrm{~Hz})$ - rapid oscillations characteristic for awake and high activity of cortex [16-18].

The alpha-waves are recorded from the parietal region in conscious and calm animals. Generally, general anesthesia is characterized by the increase of the amplitude and decrease of the frequency. However different anesthetic agents can change the neurologic response and EEG results. This can be used to evaluate the agent influence on cortical activity and patient consciousness [19-21].

\section{EEG Monitoring during General Anesthesia: Does It Improve Anesthetic Management?}

According to the classic definition of general anesthesia, it has to fulfill four basic conditions: lack (or weakening) of reflexes, analgesia, muscle relaxation, and loss of consciousness [22]. The loss of consciousness during anesthesia is obtained by a mechanism of inhibition of the central nervous system, in particular, reticular formation, thalamus, and cerebral cortex [21]. Especially the cortex is sensitive to anesthetic modulation [23]. In animals, the level of consciousness loss is assessed on the vital signs' changes and through the evaluation of observed reflexes, but it is not completely reliable since some reflexes have a neurological source outside the brain [24,25]. The lack of active reflexes also does not mean that the depth of anesthesia is appropriate, because agents such as isoflurane cause the 
immobilization first at the level of the spinal cord, and only then inhibit the transmission of nociceptive stimuli (this results from different effects on sensory and motor pathways), which is the analgesic action-one of the conditions of general anesthesia [21,26].

The use of EEG has been extensively studied in terms of its usefulness in assessing the level of general anesthesia in humans $[6,14,23,26-33]$, whereas much less of those focused on clinical application in veterinary medicine have been conducted in animals so far. The research can be divided as to the groups that have different objectives:

- techniques of good EEG practice [9]

- normal EEG measurement of healthy animal [34-36]

- $\quad$ EEG measurement during different procedures and anesthesia schemes [25,37-43]

- reactions on specific agents during general anesthesia [21,44-50].

Over $75 \%$ of neurons in the nervous system are located in the cerebral cortex. Such a large number of neurons create a highly complex multilayer structure with countless connections between themselves with constant transmission of the signals. In the autonomic nervous system, neurotransmission occurs mainly among motor plates. This results in a difference in the time of the reaction of changes in vital signs to the depression of the central nervous system by anesthetics. Life support parameters such as heart stroke volume and frequency (heart rate), constriction and dilatation of blood vessels (blood pressure, body temperature), and lung ventilation (respiratory gases level in blood, blood $\mathrm{pH}$ ) require a complex pathway of signals collected from the whole organism and are controlled by various centers of the nervous system, often cooperating with each other (for example in the blood pressure control). In case of the inhibition of the eye reflexes, there is a direct route, which significantly shortens the reaction time, because it works through the reflex arc and muscle tension.

Currently, the most common method to assess the level of anesthesia is the analysis of hemodynamic and respiratory parameters $\left(\mathrm{PaO}_{2}\right.$, heart rate, breaths per minute, $\mathrm{EtCO}_{2}$, pulse oximetry, arterial blood pressure). The dynamics of their changes depends on the stimulation of the autonomic nervous system and is partially related to the intensity of nociceptive signals. Therefore, it seems reasonable to introduce an EEG measurement due to its high specificity and sensitivity (limited number of wave patterns and a large number of variables affecting them) to show the changes of the level of consciousness, which in combination with cardiopulmonary parameters will enable accurate assessment of the patient's clinical condition during general anesthesia [40].

\section{Analysis of EEG and Its Usefulness in Equine General Anesthesia}

In equine, EEG was investigated in order to study sleep disorders and convulsions diagnostics [27, 34], but it did not find a wider clinical use due to the size of the animals and the rapid (and dangerous) course of such disorders which generated too much risk to personnel. This fortunately changes, as the new ways of safe measurements like telemetric EEG headsets have been described [35], which may open the possibilities of EEG use as a welfare test or impact of drugs [51]. Most veterinary clinics do not have the ability to perform head imaging using MRI and CT. However, it is worth the effort, because in the field of the detection of cortical disorders in horses (such as meningoencephalitis, neuronal necrosis, cerebral edema, abscess), EEG has $70 \%$ specificity and $100 \%$ sensitivity [52]. Still, in practical conditions, the clinical examination and the client interview are most common bases for diagnosis due to the limited usefulness of the EEG in the clinical practice.

Apart from the use for neurological examination, EEG has also been used in anesthesiology as a part of the anesthetic monitoring during surgery under general anesthesia. Assessment of the arousal, therefore, the depth of anesthesia through the CNS monitoring is a direct method that can significantly improve the quality of anesthesia in horses, which, due to high risk and huge difficulties in maintaining a proper level of anesthesia (especially during inhalation and balanced anesthesia), is still a challenge. Moreover, the EEG recording can be analyzed to measure the reactions on the noxious stimuli, which can help to assess a proper level of analgesia-a specific arousal pattern (increase of the frequency and 
decrease in amplitude of the EEG wave) has already been noticed in a man [16], but there is conflicting information about its occurrence in horses $[25,37,38]$. Studies have already been carried out using the EEG in small and large animals $[25,39,44,53]$, but in horses there is a need for further research introducing this method into everyday clinical practice.

The EEG recordings have been used as a method of choice for decades to diagnose epilepsy and sleep disorders such as narcolepsy and to determine the REM phase deficit [54-56]. However, the issue of general anesthesia in horses requires the search for new methods to assess the depth of anesthesia to reduce high intraoperative mortality [57]. This reason has directed the EEG research to new paths of clinical practice. The breakthrough occurred when it was introduced during balanced anesthesia. The simultaneous use of intravenous and inhalant anesthetics forced a change in the concept of assessing the depth of anesthesia. Advanced monitoring technics were needed because the use of multiple medications influences the reflexes and physiologic functions.

The application of EEG in the study of horses was conducted in specific order, so that the next research could be better, based on previous discoveries. First, the methods of electrodes' mounting and technical aspects were investigated, which were based on the previous studies on EEG as a diagnostic method for neurological disorders [56,58] (Figure 1). In horses, the electrodes should be placed in the frontal part of the skull, above the line of the eyes and below the ears. There is no need of shaving (but it enables better contact) when placing the superficial electrodes when there is a proper medium which will conduct the signal (gel, glue). The invasive electrodes are not clinically useful because their invasiveness might not be ethically accepted just for anesthesia depth assessment.

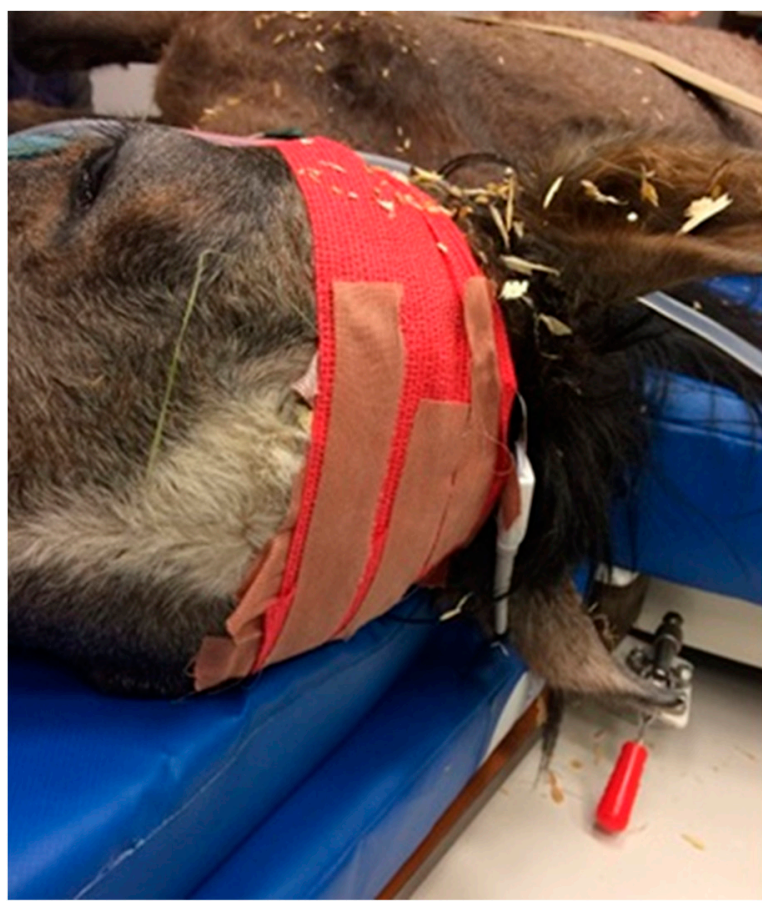

(a)

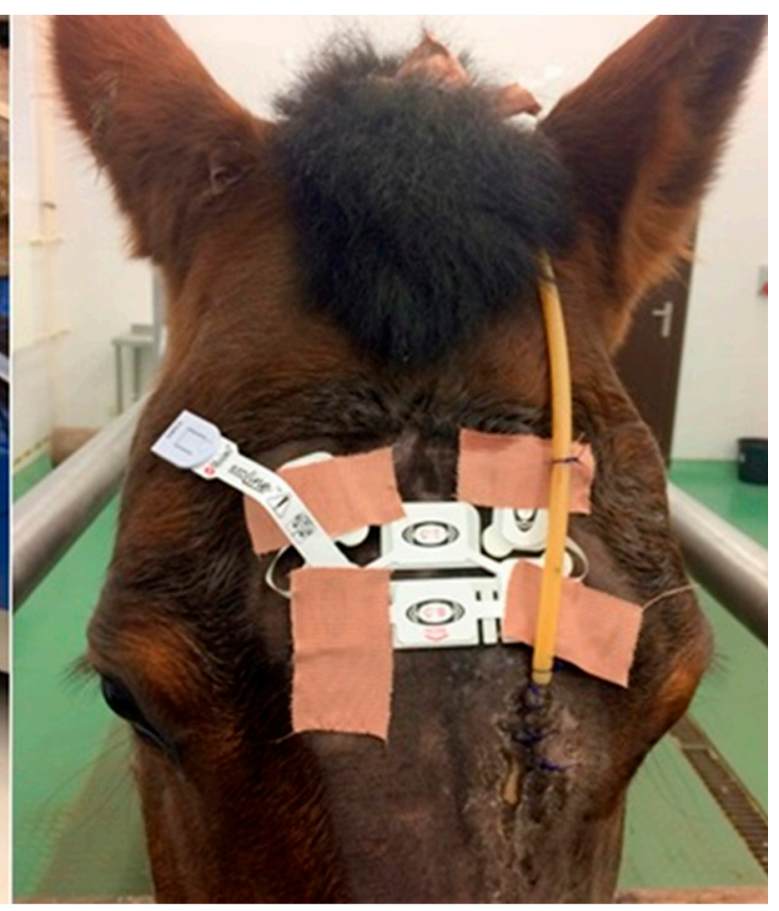

(b)

Figure 1. Placing of electroencephalography (EEG) electrodes on the parietal part of the skull in a horse (a) during general anesthesia and (b) standing anesthesia.

In the next step, the EEG of healthy horses anesthetized with specific type of agents were measured in research concerning inhalant anesthesia $[37,44,46,59]$. They found there were significant variabilities between individuals and specific time frames of measurements. More differences could be seen when comparing agents (such as isoflurane with halothane) to themselves and increasing levels of the inhalants. This also proved the fact that the analysis of raw EEG intraoperatively is not clinically useful in anesthesia depth assessment. Moreover, various intravenous agents and mixture of agents were 
described (but in most cases with inhalant adjuvant, which means it was impossible to describe the effect of single intravenous agent at the time) [46-50,53].

Another group of research focused on EEG measurement in different anesthesia schemes (based on the previous research describing EEG behavior in horses during anesthesia with use of specific agents) and during various surgical procedures characterized by different levels of amount of noxious stimuli $[38,43,60]$. During the research, three types of changes in the record were noticed:

- A typical excitation pattern, characterized by increased frequency and reduced EEG amplitude, seen in horses and dogs $[39,45]$

- Paradoxical excitation, in which the amplitude increased and the frequency of EEG decreased, seen in rats and sheep [61,62]

- "Burst suppression" characterized by sudden flattening of the wave, depending on the dose of drugs and the species $[63,64]$.

As it was already known that the raw EEG cannot be evaluated intraoperatively, it was important to obtain the fast method of frequency and quality analysis, based on described changes during application of noxious stimuli. There are several frequency domains that are numerical parameters, deducted from the spectral analysis of EEG waves-total spectral power (measure of the overall signal variability), spectral power of four frequency bands $(\alpha, \beta, \theta, \delta)$, are given as a number of percentage of total power, which shows the contribution of each band to the variability of signal, spectral edge frequency (SEF), which can be counted as F95 (the frequency under which occurs 95\% of total spectral power), F50 or mean frequency (under which occurs $50 \%$ of total spectral power), and other like F80 or F90 [28]. Until now, on the basis of the recent research, an increase in F50 and F80 has been observed during surgical stimuli in horses anesthetized with isoflurane $[37,61]$. Similar results were obtained during total intravenous anesthesia with different combinations of drugs, provided that they had a documented analgesic effect $[48,53]$.

At the next stage of research development, a mathematical analysis of the recorder EEG waves was introduced, which compares records collected during the anesthesia to the experimental EEG that was saved for every depth level of anesthesia. This results in number reflecting the depth of anesthesia counted lively during surgery. However, when using those algorithms in animals the problem is the lack of species data collected from animals. Such library (collected measurements of EEG specific for different levels of anesthesia depth) was created only for people so far, and the adequacy of results obtained by algorithms to the clinical state of patient was proved. In the case of horses, research has been conducted on the bispectral index (BI) algorithm [40,41], Narcotrend [42] and patient state index (PSI). Up to now, they were not confirmed to be accurate because of the differences in the activity of waves in humans and horses, and thus the lack of usefulness of human EEG records used for algorithms in horses only serves as study guidelines.

The latest method for real-time EEG analysis introduced in humans a few decades ago [65] is the computer analysis of EEG signals in the form of power spectrum analysis (Figure 2). Nowadays it is a standard practice in human medicine, also in assessment of agent influence on brain [33]. On the basis of mathematical analysis (Fast-Fourier Transformation-FFT), the waves are transformed into the graph, reflecting the intensity of colors in relation as the intensity of waves at a given frequency, using generally accepted limits of: $\delta(0-4 \mathrm{~Hz}), \theta(4-8 \mathrm{~Hz}), \alpha(8-13 \mathrm{~Hz})$, and $\beta(13-30 \mathrm{~Hz})$. The spectrogram (graph) changes dynamically and allows visual interpretation that can help modulate anesthesia during its duration. It is created during measurements and does not require subsequent analysis. So far there are no published results from the use of this method on animals and particularly horses, but a few of the veterinary faculties in Europe are conducting research using this system (Figure 3). 


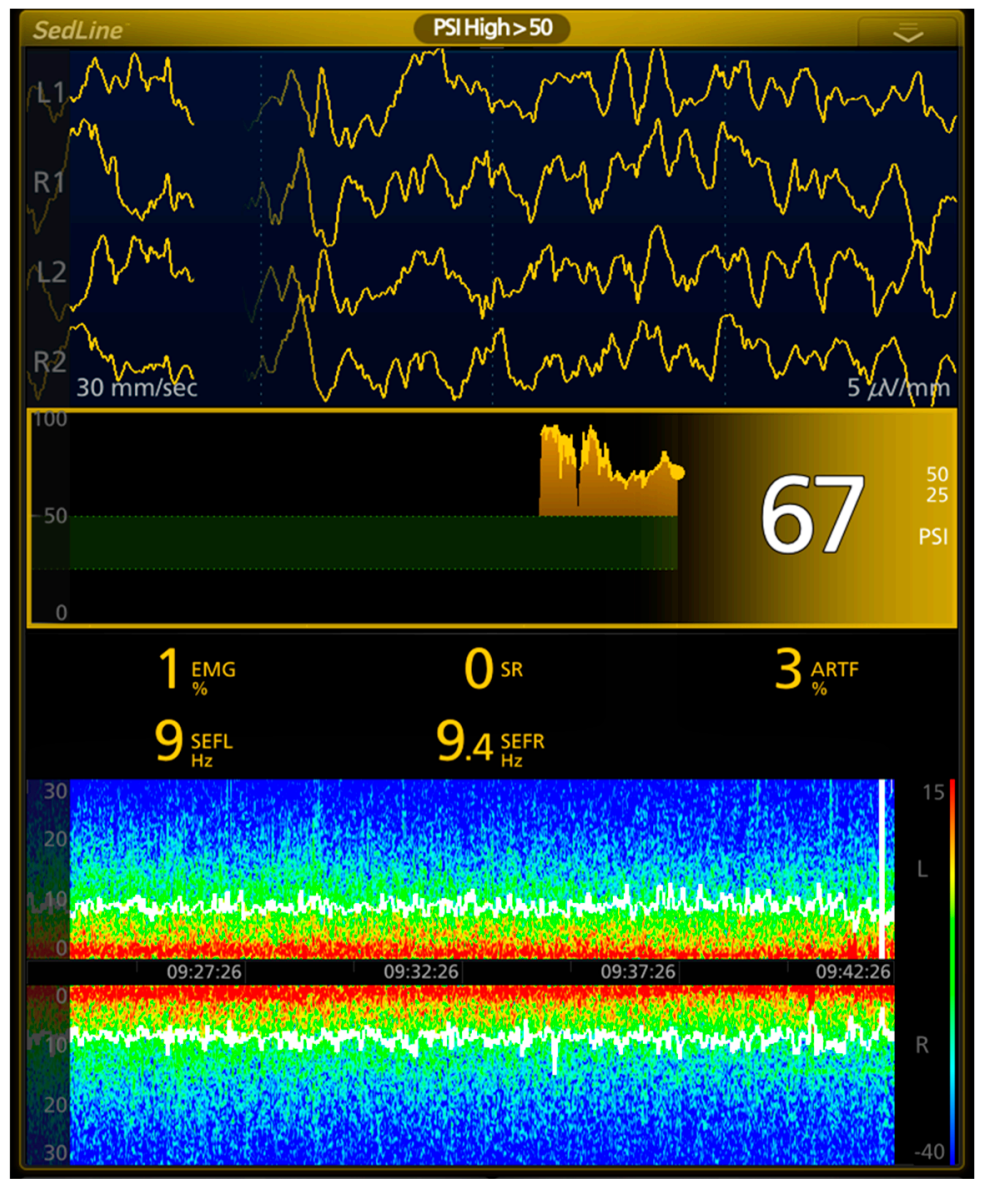

Figure 2. Spectrogram as a real-time clinically used method of EEG analysis with combination of raw EEG during computed tomography (CT) performed under general inhalant anesthesia in a horse with use of Root with Sedline ${ }^{\circledR}$, Masimo, Irvine, CA, USA.

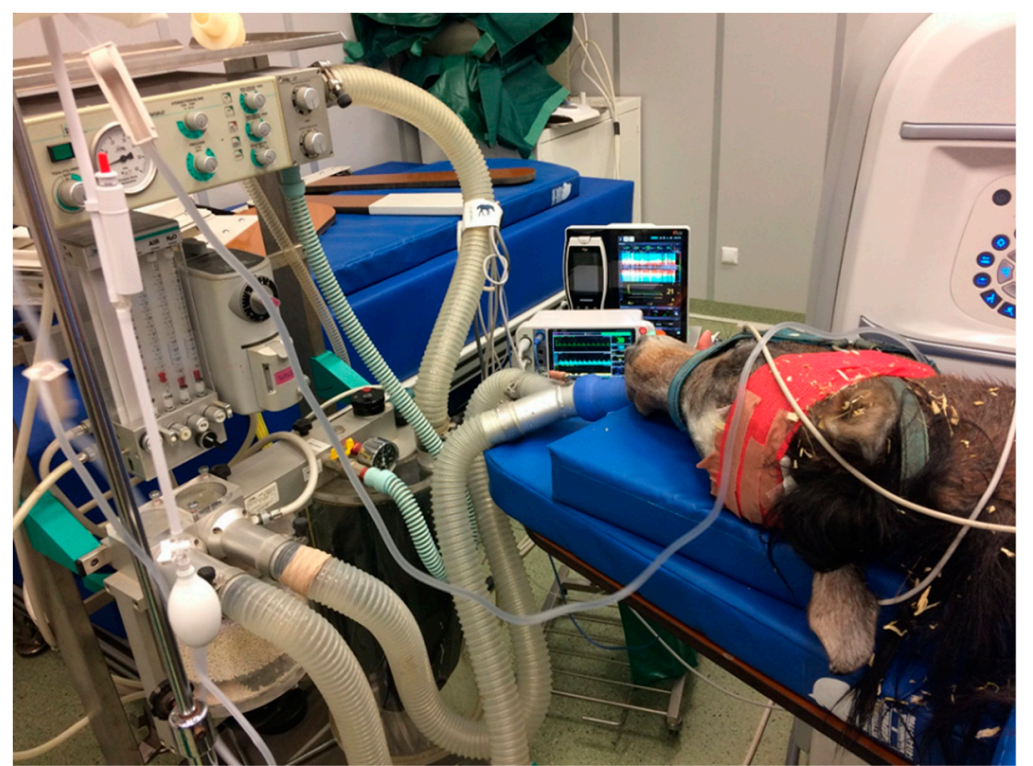

Figure 3. Parallel monitoring of vital signs and EEG analysis performer during inhalation anesthesia in computed tomography diagnostics in 11-month-old Arabian foal.

It is also worth mentioning that in horses, unlike in humans (and that is why those stages are not widely described), a big challenge is connected with the process of induction with putting the 
horse on the ground as well as with the recovery period. While the changes of the EEG activity during maintenance are rather gradual and not pronounced, which makes the EEG an additional monitoring parameter to vital sign parameters, the EEG measurement during induction and recovery can change rapidly within the loss or regaining of consciousness. As those two periods can be dangerous for a patient and the staff, it is crucial to predict when the horse is losing its consciousness and is laying down and especially when the horse is regaining consciousness and is about to move and make an attempt to stand. During that time, it is also difficult to make any other vital signs measurements and the EEG is the most sensitive to predict movement as it follows the regaining of consciousness in a short period of time. So far there was no research in that area.

Furthermore, the clinical and experimental situations which were described above and in references refer to the general anesthesia performed in fully equipped clinics. In horses, the field anesthesia is still practiced to a certain extent and it has a very limited possibility of monitoring, which makes this procedure difficult to predict and to administer suitable doses of anesthetic agents. EEG might be of help in such situations; however, the practical limitations, including the cost, have to be taken under consideration.

\section{Limitations of EEG Use and Further Research in Equine Anesthesia}

Considering the fact that the cerebral cortex lies on the surface and is much pleated, which affects the orientation of neurons, the reading of signals can be significantly different. The most important problem of EEG and MEG (magnetoencephalography) is to determine the location of neurons responsible for the propagation of the examined electrical impulses or the formation of a magnetic field in a given region. The range of potential sources of change in electric or magnetic potential that is difficult to determine is a real challenge. This problem started the interest into the combination of anatomical, physiological, and biophysical diagnostics [16].

Other technical limitations are the dependence of the EEG record on the position of the electrodes on the front part of the skull (in horses the fragment is quite wide, there are few possibilities where to place the electrodes), the effect of muscle activity around the electrodes, and the presence of reflexes (including palpebral reflex, which activates the surface head muscles) (Figure 1). Errors in evaluation can also be caused by a thick hair coat in the animal. It is also worth mentioning that because of the fact that recordings are altered by muscle activity, it is difficult to assess the EEG on a conscious (or loosing/regaining consciousness) horse. The only possibility to reach a clear recording is to use invasive deeply implanted electrodes, which application may be limited because of their invasiveness [35].

The EEG is not a completely objective method because the activity of the brain wave is also influenced by the choice of drugs administered during general anesthesia [43]. An understanding of the mode of action of each drug used for the procedure is very helpful. However, the relationship between the effects of these drugs in a predictable way has not yet been determined. A frequently noticeable change is the effect of all drugs acting via GABA receptor on the slowing down of the EEG rhythm [35]. Anesthetic drugs also affect the spinal cord independently of the cerebral cortex. This means that the analysis of only the activity of the cerebral cortex does not always allow one to predict the motor and vascular response [18]. This was seen with the development of potent sedatives such as xylazine and detomidine. They had both potent neurologic and cardiovascular effects.

It became obvious in the 1990s that the neurologic and cardiovascular evaluation of the combinations of sedatives, analgesics, and anesthetics was needed to reduce risk to the horse. A question frequently asked: is there adequate cerebral blood flow during profound sedation? The use of compressed spectral analysis of the EEGs combined with radioisotope cerebral blood flow evaluation provided the needed answers. The brain wave activity was depressed before reductions in blood flow and the desired recovery to aware state confirmed the brain had sufficient perfusion to provide needed oxygen and glucose. The duration of responses was influenced by dosages and if combined with anesthetics [66]. 
Now we have advanced technologies to conduct even more detailed evaluation of neurologic responses to anesthetics and analgesics. Finally, we have the monitors needed to determine the cerebral activity in the horse during anesthesia and surgery (Figure 2). It is expected the results of current research will make anesthetic management during surgery, full recovery, and return to normal activity of the horse more promising than ever.

\section{Conclusions}

The brain wave activity as a single parameter is not synonymous with determining the desired depht of general anesthesia, but it shows the effect of drugs on the activity of the cerebral cortex. Therefore, EEG analysis seems to be a promising technique complementary to current methods of vital signs' monitoring used to determine a stable level of general anesthesia. Its possible usefulness in horses requires a broader understanding of EEG wave changes under balanced anesthesia using different methods and determining the ranges of waves synonymous with deep sleep to profound anesthesia and analgesia. Future studies hopefully will improve our ability to adapt the currently used technologies in human hospitals for use in equine anesthesia and pain management.

Author Contributions: O.D. performed the investigation and literature analysis, drew the conceptualization, and prepared the original draft; B.L. took care of validation and review; B.T. did the final review and editing.

Acknowledgments: Authors would like to thank Charles Short for the support in the process of writing as well as valuable comments.

Conflicts of Interest: The authors declare no conflict of interest.

\section{References}

1. Noachtar, S.; Binnie, C.; Ebersole, J. A glossary of terms most commonly used by clinical electroencephalographers and proposal for the report form for the EEG findings. Klin. Neurophysiol. 2004, 35, 5-21.

2. Tooley, M.A.; Grant, L.J.; Davies, A.R. A micoprocessor based instrument for the spectral analysis of the EEG in anaesthesia. Clin. Phys. Physiol. Meas. 1984, 5, 303-311. [CrossRef] [PubMed]

3. Guedel, A.E. Third stage ether anesthesia: A sub-classification regarding the significance of the position and movements of the eyeball. Pa Med. J. 1921, 24, 375-380. [CrossRef]

4. Rampil, I.J. Monitoring depth of anesthesia. Curr. Opin. Anaesthesiol. 2001, 14, 649-653. [CrossRef]

5. Aminoff, M.J. Electroencephalography: General principles and clinical applications. In Electrodiagnosis in Clinical Neurology; Aminoff, M.J., Ed.; Churchill Livingstone: New York, NY, USA, 1986; pp. 21-75.

6. Klemm, W.R. Electroencephalography in the diagnosis of epilepsy. Probl. Vet. Med. 1989, 1, 535-557. [PubMed]

7. Croft, P.G. The EEG as an aid to diagnoses of nervous diseases in the dog and cat. J. Small Anim. Pract. 1964, 5, 540-541.

8. Holliday, T.A.; Cunningham, J.G.; Gutnick, M.J. Comparative clinical and electroencephalographic studies of canine epilepsy. Epilepsia 1970, 11, 281-292. [CrossRef] [PubMed]

9. Redding, R.W. A simple technique for obtaining an electroencephalogram of the dog. Am. J. Vet. Res. 1964, $25,854-857$.

10. Usenick, M.W.; Kitchell, R.L.; Herschler, R.G. The EEG as an aid to diagnosis of nervous diseases in the dog and cat. J. Small Anim. Pract. 1962, 3, 205-208.

11. Swanson, L.W. What is the brain? Trends Neurosci. 2000, 23, 519-527. [CrossRef]

12. Lemke, K.A. Understanding the pathophysiology of perioperative pain. Can. Vet. J. 2004, 45, 405. [PubMed]

13. Furness, J.B. The organisation of the autonomic nervous system: Peripheral connections. Auton. Neurosci. Basic Clin. 2006, 130, 11-15. [CrossRef] [PubMed]

14. Deco, G.; Jirsa, V.K.; Robinson, P.A.; Breakspear, M.; Friston, K. The dynamic brain: From spiking neurons to neural masses and cortical fields. PLoS Comput. Biol. 2008, 4, e1000092. [CrossRef] [PubMed]

15. Hess, A.; Sergejeva, M.; Budinsky, L.; Zeilhofer, H.U.; Brune, K. Imaging of hyperalgesia in rats by functional MRI. Eur. J. Pain 2007, 11, 109-119. [CrossRef] [PubMed]

16. da Silva, F.L. EEG: Origin and Measurement. In EEG—Fmri; Mulert, C., Lemieux, L., Eds.; Springer: Berlin, Germany, 2009. 
17. Constant, I.; Sabourdin, N. The EEG signal: A window on the cortical brain activity. Pediatric Anesth. 2012, 22, 539-552. [CrossRef]

18. Jameson, L.C.; Sloan, T.B. Using EEG to monitor anesthesia drug effects during surgery. J. Clin. Monit. Comput. 2006, 20, 445-472. [CrossRef] [PubMed]

19. Choi, B.M. Characteristics of electroencephalogram signatures in sedated patients induced by various anesthetic agents. J. Dent. Anesth. Pain Med. 2017, 17, 241-251. [CrossRef] [PubMed]

20. Purdon, P.L.; Sampson, A.; Pavone, K.J.; Brown, E.N. Clinical electroencephalography for anesthesiologists part I: Background and basic signatures. Anesthesiol. J. Am. Soc. Anesthesiol. 2015, 123, 937-960.

21. Antognini, J.F.; Wang, X.W.; Carstens, E. Isoflurane action in the spinal cord blunts electroencephalographic and thalamic-reticular formation responses to noxious stimulation in goats. Anesthesiol. J. Am. Soc. Anesthesiol. 2000, 92, 559. [CrossRef]

22. Steffey, E.P. Concepts of general anesthesia and assessment of adequacy of anesthesia for animal surgery. In Animal Pain; Kitchell, R.L., Erickson, H.H., Eds.; Springer: New York, NY, USA, 1983; pp. 133-150.

23. Steriade, M.; Amzica, F.; Contreras, D. Cortical and thalamic cellular correlates of electroencephalographic burst-suppression. Electroenceph. Clin. Neurophysiol. 1994, 90, 1-16. [CrossRef]

24. Eger, E.; Saidman, L.; Brandstater, B. Minimum alveolar anesthetic concentration: A standard of anesthetic potency. Anesthesiology 1965, 26, 756-763. [CrossRef] [PubMed]

25. Otto, K.A.; Voigt, S.; Piepenbrock, S. Differences in quantitated electroencephalographic variables during surgical stimulation of horses anesthetized with isoflurane. Vet. Surg. 1996, 25, 249-255. [CrossRef]

26. Bovill, J.G.; Antognini, J.F.; Atherley, R.; Carstens, E. Isoflurane action in spinal cord indirectly depresses cortical activity associated with electrical stimulation of the reticular formation. Anesth. Analg. 2003, 96, 999-1003. [CrossRef] [PubMed]

27. Dunigan, C.E.; Oglesbee, M.J.; Podell, M. Seizure activity associated with equine protozoal myeloencephalitis. Progr. Vet. Neurol. 1995, 6, 50-54.

28. Bimar, J.; Bellville, J.W. Arousal reactions during anesthesia in man. Anesthesiology 1977, 47, 449-454. [CrossRef] [PubMed]

29. Long, C.W.; Shah, N.K.; Loughlin, C. A comparison of EEG determinants of near-awakening from iso£urane and fentanyl anesthesia. Anesth. Analg. 1989, 69, 169-173. [CrossRef] [PubMed]

30. Rampil, I.J.; Matteo, R.S. Changes in EEG spectral edge frequency correlate with the haemodynamic response to laryngoscopy and intubation. Anaesthesiology 1987, 67, 139-142. [CrossRef] [PubMed]

31. Schwender, D.; Daunderer, M.; Mulzer, S. Spectral edge frequency of the electroencephalogram to monitor 'depth' of anaesthesia with iso£urane or propofol. Br. J. Anaesth. 1996, 77, 179-184. [CrossRef]

32. Huang, H.H.; Lee, Y.H.; Chan, H.L.; Wang, Y.P.; Huang, C.H. Using a short-term parameter of heart rate variability to distinguish awake from isoflurane anesthetic states. Med. Biol. Eng. Comput. 2008, 46, 977-984. [CrossRef]

33. Akeju, O.; Westover, M.B.; Pavone, K.J.; Sampson, A.L.; Hartnack, K.E.; Brown, E.N.; Purdon, P.L. Effects of sevoflurane and propofol on frontal electroencephalogram power and coherence. Anesthesiology 2014, 121, 990-998. [CrossRef]

34. Giovagnoli, G.; de Feo, M.R.; Frascarelli, M. The use of EEG and ECG ambulatory technique in horses: Preliminary observations. Pferdeheilkunde 1996, 12, 446-449.

35. Cousillas, H.; Oger, M.; Rochais, C.; Pettoello, C.; Ménoret, M.; Henry, S.; Hausberger, M. An Ambulatory Electroencephalography System for Freely Moving Horses: An Innovating Approach. Front. Vet. Sci. 2017, 4, 57. [CrossRef] [PubMed]

36. Mysinger, P.W.; Redding, R.W.; Vaughan, J.T.; Purohit, R.C.; Holladay, J.A. Electroencephalographic patterns of clinically normal, sedated and tranquilized newborn foals and adult horses. Am. J. Vet. Res. 1985, 46, 36-41. [PubMed]

37. Ekstrom, P.M.; Short, C.E.; Geimer, T.R. Electroencephalography of detomidine-ketamine-halothane and detomidine-ketamine-isoflurane anesthetized horses during surgery: A comparison. Vet. Surg. 1993, 22, 414-418. [CrossRef] [PubMed]

38. Miller, S.M.; Short, C.E.; Ekstrom, P.M. Quantitative electroencephalographic evaluation to determine the quality of analgesia during anesthesia of horses for arthroscopic surgery. Am. J. Vet. Res. 1995, 56, 374-379. [PubMed] 
39. Murrell, J.C.; Johnson, C.B.; White, K.L. Changes in the EEG during castration in horses and ponies anaesthetized with halothane. Vet. Anaesth. Analg. 2003, 30, 138-146. [CrossRef] [PubMed]

40. Tokushige, H.; Kakizaki, M.; Ode, H.; Okano, A.; Okada, J.; Kuroda, T.; Wakuno, A.; Ohta, M. Validation of the bispectral index as an indicator of anesthetic depth in Thoroughbred horses anesthetized with sevoflurane. J. Equine Sci. 2016, 27, 169-173. [CrossRef] [PubMed]

41. Yamashita, K.; Akashi, N.; Katayama, Y.; Uchida, Y.; Umar, M.A.; Itami, T.; Inoue, H.; Sams, R.A.; MUIR, W.W., III. Evaluation of bispectral index (BIS) as an indicator of central nervous system depression in horses anesthetized with propofol. J. Vet. Med Sci. 2009, 71, 1465-1471. [CrossRef] [PubMed]

42. Tünsmeyer, J.; Hopster, K.; Kästner, S.B. Clinical Use of a Multivariate electroencephalogram (narcotrend) for assessment of anesthetic Depth in horses during isoflurane-Xylazine anesthesia. Front. Vet. Sci. 2016, 3, 25. [CrossRef]

43. Short, C.E.; Ekstrom, P.M. Compressed spectral analysis of the EEG as an indicator of anesthetic quality during anesthesia for orthopedic surgery in the horses. In Proceedings of the Annual Convention of the American Association of Equine Practitioners, San Antonio, TX, USA, 5-8 December 1993.

44. Auer, J.A.; Amend, J.F.; Garner, H.E. Electroencephalographic responses during volatile anesthesia in domestic ponies: A comparative study of isoflurane, enflurane, methoxyflurane, and halothane. J. Equine Med. Surg. 1979, 3, 130-134.

45. Kongara, K.; Chambers, J.P.; Johnson, C.B. Electroencephalographic responses of tramadol, parecoxib and morphine to acute noxious electrical stimulation in anaesthetised dogs. Res. Vet. Sci. 2010, 88, 127-133. [CrossRef] [PubMed]

46. Murrell, J.C.; White, K.L.; Johnson, C.B.; Taylor, P.M.; Doherty, T.J.; Waterman-Pearson, A.E. Investigation of the EEG effects of intravenous lidocaine during halothane anaesthesia in ponies. Vet. Anaesth. Analg. 2005, 32, 212-221. [CrossRef] [PubMed]

47. Otto, K.A.; Voigt, S.; Piepenbrock, S.; Deegen, E. Effects of low dose ketamine on haemodynamic and electroencephalographic variables during surgery in isoflurane anaesthetised horses. J. Vet. Anaesth 1998, 25, 8-12. [CrossRef]

48. Johnson, C.B.; Bloomfield, M.; Taylor, P.M. Effects of ketamine on the equine electroencephalogram during anesthesia with halothane in oxygen. Vet. Surg. 1999, 28, 380-385. [CrossRef] [PubMed]

49. Johnson, C.B.; Bloomfield, M.; Taylor, P.M. Effects of guaiphenesin on the equine electroencephalogram during anaesthesia with halothane in oxygen. Vet. Anaesth. Analg. 2000, 27, 6-12. [CrossRef]

50. Johnson, C.B.; Bloomfield, M.; Taylor, P.M. Effects of thiopentone on the equine electroencephalogram during anaesthesia with halothane in oxygen. Vet. Anaesth. Analg. 2000, 27, 82-88. [CrossRef] [PubMed]

51. Rochai, C.; Henry, S.; Fureix, C.; Hausberger, M. Investigating attentional processes in depressive-like domestic horses (Equus caballus). Behav. Process. 2016, 124, 93-96. [CrossRef] [PubMed]

52. Lacombe, V.A.; Podell, M.; Furr, M. Diagnostic validity of electroencephalography in equine intracranial disorders. J. Vet. Intern. Med. 2001, 15, 385-393. [CrossRef] [PubMed]

53. Johnson, C.B.; Taylor, P.M. Comparison of the effects of halothane, isoflurane and methoxyflurane on the electroencephalogram of the horse. Br. J. Anaesth. 1998, 81, 748-753. [CrossRef]

54. Fuchs, C. Narkolepsie oder REM-Schlafmangel? Ph.D. Thesis, LMU München, Tierärztliche Fakultät, Munich, Germany, 2017.

55. van der Ree, M.; Wijnberg, I. A review on epilepsy in the horse and the potential of Ambulatory EEG as a diagnostic tool. Vet. Q. 2012, 32, 159-167. [CrossRef]

56. Wijnberg, I.D.; van Der Ree, M.; van Someren, P. The applicability of ambulatory electroencephalography (AEEG) in healthy horses and horses with abnormal behaviour or clinical signs of epilepsy. Vet. Q. 2013, 33, 121-131. [CrossRef] [PubMed]

57. Johnston, G.M.; Taylor, P.M.; Holmes, M.A. The confidential enquiry of perioperative equine fatalities (CEPEF-1): Preliminary results. Equine Vet. J. 1998, 27, 193-200. [CrossRef] [PubMed]

58. Haga, H.A.; Dolvik, N.I. Electroencephalographic and cardiovascular variables as nociceptive indicators in isoflurane-anaesthetized horses. Vet. Anaesth. Analg. 2005, 32, 128-135. [CrossRef]

59. Williams, D.C.; Aleman, M.R.; Brosnan, R.J.; Fletcher, D.J.; Holliday, T.A.; Tharp, B.; Kass, P.H.; Steffey, E.P.; Lecouteur, R.A. Electroencephalogram of healthy horses during inhaled anesthesia. J. Vet. Intern. Med. 2016, 30, 304-308. [CrossRef] [PubMed] 
60. Grint, N.J.; Johnson, C.B.; Lorena, S.D.S.; Luna, S.; Hussni, C.A.; Whay, H.R.; Murrell, J.C. Electroencephalographic responses to a noxious surgical stimulus in mules, horses, and ponies. J. Equine Vet. Sci. 2014, 34, 955-962. [CrossRef]

61. Otto, K.A.; Mally, P. Noxious stimulation during orthopaedic surgery results in EEG 'arousal' and 'paradoxical arousal' reaction in isoflurane-anaesthetised sheep. Res. Vet. Sci. 2003, 75, 103-112. [CrossRef]

62. Diesch, T.J.; Mellor, D.J.; Johnson, C.B.; Lentle, R.G. Electroencephalographic responses to tail clamping in anaesthetized rat pups. Lab. Anim. 2009, 43, 224-231. [CrossRef] [PubMed]

63. Haskins, S.C. Monitoring the anesthetized patient. In Lumb and Jones Veterinary Anesthesia, 3rd ed.; Thurmon, J.C., Tranquilli, W.J., Benson, G.J., Eds.; Williams and Wilkins: Baltimore, MD, USA, 1996; pp. 409-424.

64. Steffey, E.P. Inhalation anesthetics. In Lumb and Jones Veterinary Anesthesia, 3rd ed.; Thurmon, J.C., Tranquilli, W.J., Benson, G.J., Eds.; Williams and Wilkins: Baltimore, MD, USA, 1996; pp. 297-329.

65. Bickford, R.G.; Fleming, N.; Billinger, T. Compression of EEG data. Trans. Am. Neurol. Assoc. 1971, 96, 118-122. [PubMed]

66. Short, C.E.; Kallfelz, F.A.; Otto, K.; Otto, B.; Wallace, R. The effects of alpha 2-adrenocepter agonist analgesia on the central nervous system in an equine model. In Animal Pain; Short, C.E., Van Poznak, A., Eds.; Churchill Livingstone: New York, NY, USA, 1992.

(C) 2019 by the authors. Licensee MDPI, Basel, Switzerland. This article is an open access article distributed under the terms and conditions of the Creative Commons Attribution (CC BY) license (http://creativecommons.org/licenses/by/4.0/). 